\title{
Giraffes, Institutions and Neglected Firms
}

\author{
Avner Arbel, Cornell University \\ Steven Carvell, SUNY Binghamton \\ Paul Strebel, SUNY Binghamton
}

\begin{abstract}
Certain securities-in particular, those of small capitalization firms-are generally unsuited to the investment requirements of financial institutions, hence attract minimal coverage by analysts. As a result, these securities may offer a premium as a compensation for associated information deficiencies and/or because pricing inefficiencies exist as a result of the lack of information.
\end{abstract}

An analysis of 510 firms over a 10-year period indicates that the shares of those firms neglected by institutions outperform significantly the shares of firms widely held by institutions. The superior performance persists over and above any "small firm effect"; that is, both small and medium-sized neglected firms exhibit superior performance. The "neglected firm effect" suggests some potentially rewarding investment strategies for individuals and institutions alike.

\section{Introduction}

Institutions, mutual funds, banks and money managers are somewhat like giraffes. Both for good structural reasons and as a matter of preference they concentrate on the tall trees in the investment forest, ignoring the underbrush.

Structurally, institutions face several difficulties in investing in firms with small capitalizations. First, the typical size of an institutional investment could affect the price, hence the liquidity, of low capitalization, thinly traded securities. Second, such an investment would frequently result in more than 5 per cent ownership, requiring an insider's report to comply with Securities and Exchange Commission regulations. Third, the holding could quickly become large enough to necessitate managerial input, which often falls outside the institution's area of interest and expertise.

With respect to their preferences, institutional fund managers may not want to take the greater risk perceived to be associated with small firms. They are expected to follow a prudent investment policy, which frequently means doing what everybody else does. Also, many institutions require that an investment yield dividend income, and few small firms do. 
As a result of these and other external and internal constraints that affect the investment behavior of financial institutions, we might expect to find some market segmentation, with certain securities being continuously neglected by institutional investors. And, indeed, several recent studies of analysts' coverage of firms indicated that a "neglected firm effect" persisted during the 10-year period from 1970 to $1979 .{ }^{1}$ Furthermore, those firms that were relatively neglected by security analysts exhibited market performance superior to that of highly researched firms: The most neglected securities in the Standard \& Poor's 500 had an average annual return, including dividends, of 16.4 per cent, compared with 9.4 per cent for the highly followed group. Most importantly, the neglected firm effect persisted after the usual adjustments for risk (systematic, unsystematic and total volatility), and it existed not only among small capitalization companies but, to a large extent, across firm size.

A key question not covered in previous studies is whether the neglected firm effect persists when "neglect" is measured in terms of actual investment by institutions, rather than merely analyst attention. The answer to this question may provide a better understanding of the neglected firm effect and the factors underlying it. It could also offer a more explicit and readily available measure of neglect for those wishing to implement a neglected firm investment strategy. Finally, testing a different measure of neglect provides an additional check of the neglected firm effect and its interaction with other factors such as size. ${ }^{2}$

\section{Measuring Neglect}

Perhaps the most obvious ex post measure of neglect relates to financial institutions' holdings. It is easy to identify stocks that are neglected by the institutions and to compare their market performance with that of stocks more intensively held by institutions. The concentration of institutions on some securities rather than others raises several questions. Is this phenomenon important enough to create significant market segmentation? If so, does it affect the market pricing mechanism? In particular, do those securities neglected by the institutions consistently perform better or worse? If differences in pricing exist, can investors benefit from it? Finally, and perhaps most importantly for institutional investors, are only small firms neglected? If not, how do the larger institutionally neglected companies perform?

\section{Method}

We studied a random sample of 510 companies, drawn in equal numbers from the New York Stock Exchange, the American Stock Exchange and the over-the-counter markets, over the 10 -year period 1971 to 1980 . These firms were divided into three broad Institutional Concentration Rankings (ICR) according to institutional holding data published by Standard \& Poor's; ICR 1 comprised the securities most intensively held by institutions and ICR 3 the "institutionally neglected securities." 3 This division gave clear evidence that market segmentation does exist: About one-third of the companies in the random cross-market sample were neglected by financial institutions-i.e., held by no institution at all, or by just one. 
Given recent findings about the "small firm effect" and the importance of company size in the institutional investment decision, we devoted special attention to the relationship between size and neglect. ${ }^{4}$ Firms within each ICR group were ranked by their market capitalizations (the average of the yearly high and low market prices times the number of shares outstanding) and then divided into three size groups, Si containing the smallest and S3 the largest firms. This resulted in nine portfolios, which were rebalanced annually for changes in institutional holdings and market capitalization.

We calculated monthly returns for each portfolio based on the equally weighted monthly return for all the securities included in the portfolio during the year. Portfolio betas, as well as excess returns, were then calculated using the Capital Asset Pricing Model, with both the equally weighted and value-weighted versions of the Wilshire 5000 Index (which consists of the returns on all securities actively traded during a given period in all markets) serving as the proxies. ${ }^{5}$

Because many practitioners believe that standard deviation of returns measures risk better than the beta coefficient, we computed the standard deviations of the nine portfolios. For the sake of completeness, we also considered the unsystematic risk measures generated by the Capital Asset Pricing Model. Using these several different risk measures, we compared the portfolios' risk adjusted performances in terms of the Sharpe index (returns per unit of total risk) and the Treynor index (returns per unit of systematic risk), as well as with respect to average excess returns and returns per unit of unsystematic risk. ${ }^{6}$

\section{Relative Performance}

Table I lists the average annual portfolio returns, risk measures and risk-adjusted returns for the three ICR portfolios. The pattern of returns suggests a marked neglected firm effect. For the decade as a whole, the average annual return for the institutionally neglected securities (20.8 per cent) was twice that of the stocks most widely held by financial institutions (10.4 per cent).

Table I Average Annual Returns, Risk Measures and Risk-Adjusted Returns By Institutional Holding (ICR), 1971-1980

\begin{tabular}{lc|cc|ccc}
\hline & Return $^{\mathrm{a}}$ & \multicolumn{2}{|c|}{ Risk } & \multicolumn{3}{c}{ Risk-Adjusted Returns } \\
\cline { 2 - 7 } $\begin{array}{l}\text { Institutional } \\
\begin{array}{l}\text { Concentration } \\
\text { Ratio (ICR) }\end{array}\end{array}$ & $\begin{array}{c}\text { Total } \\
\sigma\end{array}$ & $\begin{array}{c}\text { Systematic } \\
\beta\end{array}$ & $\begin{array}{c}\text { Excess } \\
\text { Return }^{\mathrm{b}}\end{array}$ & $\begin{array}{c}\text { Sharpe } \\
\text { Index }\end{array}$ & $\begin{array}{c}\text { Treynor } \\
\text { Index }\end{array}$ \\
\hline $\begin{array}{l}\text { ICR 1: } \\
\text { Intensively Held }\end{array}$ & $\begin{array}{l}0.1036 \\
(0.028)\end{array}$ & 0.337 & 0.99 & -0.0580 & 0.12 & 0.040 \\
$\begin{array}{l}\text { ICR 2: } \\
\text { Moderately Held }\end{array}$ & $\begin{array}{l}0.1689 \\
(0.036)\end{array}$ & 0.428 & 0.92 & 0.0111 & 0.25 & 0.114 \\
$\begin{array}{l}\text { ICR 3: } \\
\text { Institutionally }\end{array}$ & $\begin{array}{l}0.2084 \\
\text { Neglected }\end{array}$ & 0.536 & 0.90 & 0.0564 & 0.27 & 0.160 \\
\hline
\end{tabular}

a Standard errors of estimates are given in parentheses.

b Based on the Capital Asset Pricing Model. 
In gauging relative performance, returns must, of course, be adjusted for risk. The risk measures presented in Table I indicate that total risk does increase with the degree of neglect (although market-related risk declines slightly). Nevertheless, on average the neglected ICR 3 portfolios earned more than double or quadruple the return per unit of risk than the widely held ICR 1 portfolios, depending on whether the risk adjustment was done with total risk (Sharpe index) or with beta (Treynor index). Furthermore, the widely held ICR 1 portfolio had an average annual excess return of negative 8.58 per cent, whereas the neglected ICR 3 portfolio was 5.64 per cent above the market.

Table II Risk Measures By Institutional Holding (ICR) and Company Size, 1971-1980

\begin{tabular}{|c|c|c|c|c|}
\hline \multirow{2}{*}{\multicolumn{2}{|c|}{$\begin{array}{l}\text { Institutional } \\
\text { Concentration } \\
\text { Ratio (ICR) }\end{array}$}} & \multicolumn{3}{|c|}{ Company Size } \\
\hline & & S1:Small & S2:Medium & S3:Large \\
\hline $\begin{array}{r}\text { ICR 1: } \\
\text { (a) } \\
\text { (b) } \\
\text { (c) }\end{array}$ & $\begin{array}{l}\text { Intensively Held } \\
\text { Systematic risk (beta) } \\
\text { Total risk } \\
\text { Returns }\end{array}$ & a & $\begin{array}{l}0.82 \\
0.434 \\
0.086\end{array}$ & $\begin{array}{l}0.70 \\
0.331 \\
0.109\end{array}$ \\
\hline $\begin{array}{r}\text { ICR 2: } \\
\text { (a) } \\
\text { (b) } \\
\text { (c) }\end{array}$ & $\begin{array}{l}\text { Moderately Held } \\
\text { Systematic risk (beta) } \\
\text { Total risk } \\
\text { Returns }\end{array}$ & $\begin{array}{l}1.07 \\
0.467 \\
0.147\end{array}$ & $\begin{array}{l}0.95 \\
0.408 \\
0.173\end{array}$ & $\begin{array}{l}0.73 \\
0.374 \\
0.232\end{array}$ \\
\hline $\begin{array}{r}\text { ICR 3: } \\
\text { (a) } \\
\text { (b) } \\
\text { (c) }\end{array}$ & $\begin{array}{l}\text { Institutionally Neglected } \\
\text { Systematic risk (beta) } \\
\text { Total risk } \\
\text { Returns }\end{array}$ & $\begin{array}{l}1.10 \\
0.553 \\
0.201\end{array}$ & $\begin{array}{l}0.92 \\
0.436 \\
0.260\end{array}$ & a \\
\hline $\begin{array}{l}\text { Mean } \\
\text { (a) } \\
\text { (b) } \\
\text { (c) }\end{array}$ & $\begin{array}{l}\text { Systematic risk (beta) } \\
\text { Total risk } \\
\text { Returns }\end{array}$ & $\begin{array}{l}1.24 \\
0.523 \\
0.184\end{array}$ & $\begin{array}{l}0.90 \\
0.397 \\
0.163\end{array}$ & $\begin{array}{l}0.70 \\
0.338 \\
0.122\end{array}$ \\
\hline
\end{tabular}

a. Meaningless because of small number of cases in this category.

\section{Size Effect}

Is the neglected firm effect just a reflection of the size effect? Tables II and III present the evidence on the relationship between neglect and company size. The findings in Table II indicate a significant neglected firm effect across all size groups; in all three columns, portfolio returns rise sharply with declining institutional holdings as measured by the ICR groupings. Evidence of superior returns on small firms is only apparent in the sample as a whole (last row); among the firms preferred by institutions (ICRs 1 and 2), the larger firms performed better. This suggests the small firm effect may be a reflection of the neglected firm effect, rather than the other way around.

Table II also contains various risk measures. ${ }^{7}$ Whereas beta does not vary systematically with differences in degree of neglect (down the columns), it does vary with size. The small-firm portfolios have significantly higher betas than the large-firm portfolios (across the rows). In other words, systematic (market-related) risk decreases with size, but is largely unaffected by institutional attention. Unsystematic risk, on the other hand, increases slightly with degree of 
neglect but declines with size; the same applies for total risk, which is the sum of the systematic and unsystematic risks.

Table III Risk-Adjusted Returns By Institutional Holding (ICR) and Company Size, 1971-1980

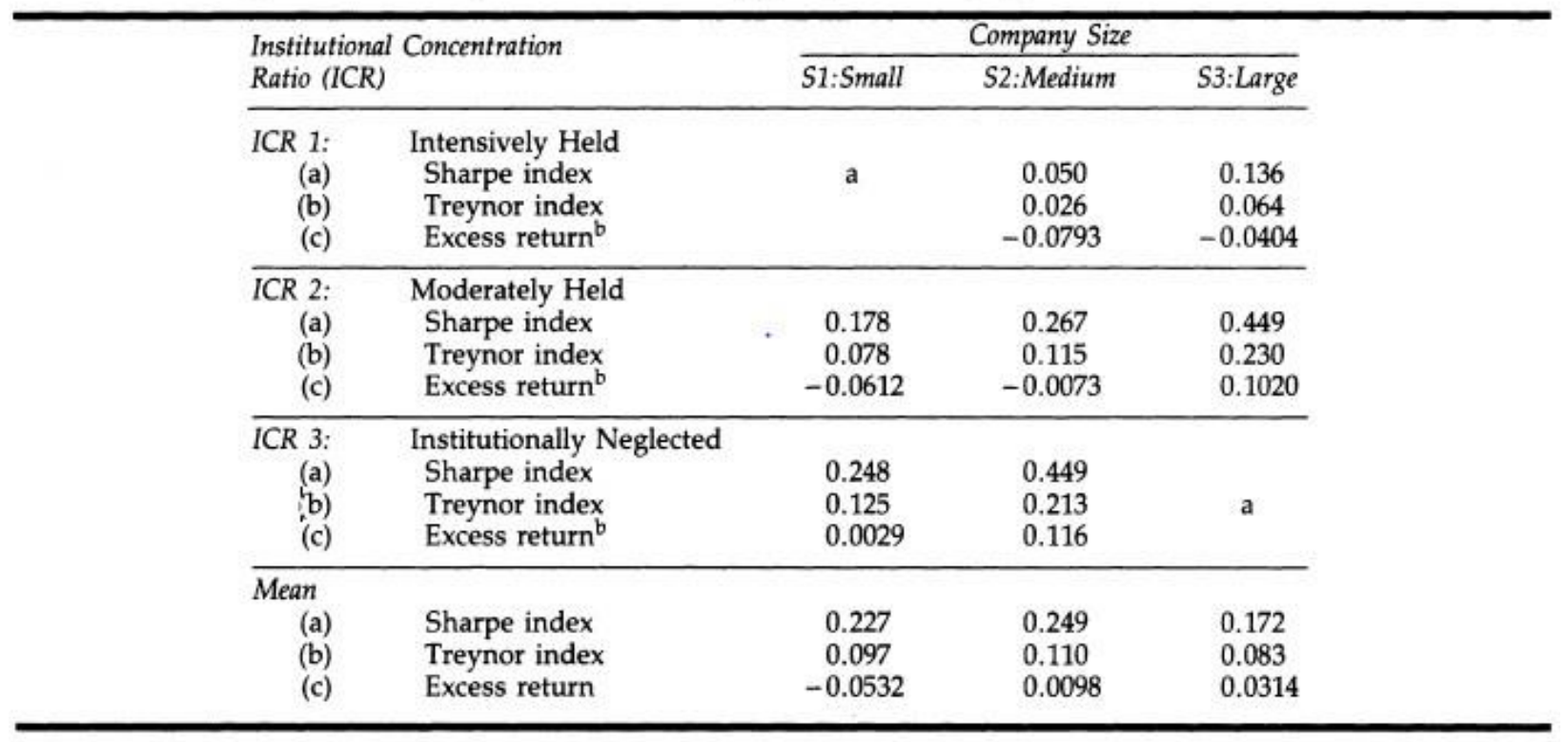

a. Meaningless due to small number of cases in this category

b. According to the Capital Asset Pricing Model.

Table III presents risk-adjusted return measures. A strong neglected firm effect persists even when size is controlled. On the other hand, no systematic small firm effect is evident. Although still weakly apparent in terms of the Sharpe and Treynor indexes for the sample as a whole, the small firm effect disappears when measured by excess returns relative to the equally weighted market index. Since an equally weighted index corrects for the small firm effect by reducing the betas of large firms and raising those of small firms, this result may have been expected. The important point, however, is that firms neglected by institutions outperformed widely held firms on a risk-adjusted basis, even after correcting for the size effect by both using an equally weighted index and forming equal-size portfolios.

\section{Interpretation}

Given previous evidence of the existence of a neglected firm effect when neglect was measured by an informational parameter (analysts' coverage), it is not surprising that the same effect was found when an institutional measure of neglect was used. After all, institutions' predilections play a large role in determining the research concentration of analysts, since a lot of investment research is done by and for institutions.

Because of external constraints (e.g., the five per cent rule, liquidity needs) and selfimposed policies (e.g., "prudent" investment policy), institutions consistently avoid certain companies. Informational vacuums ("neglect") follow, whereby some companies get very limited coverage by analysts. According to this scenario, the neglected segment of the market is in effect an informational outcome of the barriers that constrain the market activities of 
financial institutions. In this context, the superior returns on institutionally neglected firms can be attributed to two factors, each with practical import.

\section{Information Deficiency Premium}

Consumers are willing to pay a price for the quality, or certainty, of information about a product. The obvious examples are brand-name versus generic products and franchised versus independent services. Consumers demand a discount on items with low quality information to compensate them for the additional uncertainty involved or for the cost of acquiring the information to avoid this uncertainty.

The neglected firm effect suggests that the same process is at work in the financial markets. Institutional ownership not only implies a stamp of approval based on the more extensive research capability of institutions relative to private investors, but it also generates more information about the security. The availability of higher quality information raises the price of the security and lowers its return relative to the return on neglected securities. This quality of information factor is not captured by the usual measures of risk. Thus, in more technical terms, one can attribute the observed abnormal returns on neglected stocks to the fact that the Capital Asset Pricing Model is missing a relevant variable, one that would explain the apparent premium for information deficiency. The lunch, again, is not free.

\section{$\underline{\text { Inefficient Pricing }}$}

It may be that the neglected segment of the market offers abnormal returns over and above the information deficiency premium because of an inefficient pricing process that is, in effect, an outcome of the information deficiency itself. The same information deficiency that generates the premium creates a market environment wherein inefficient pricing can occur, causing some securities, at least for a while, to be overpriced or underpriced.

The factors that make it costly for institutions to invest in certain firms represent a market barrier separating institutions and other investors. If, after adjustment for any information deficiency premium, the excess returns on neglected securities are greater than the market barrier, institutions will obviously step in to take advantage of the difference and eliminate the abnormal returns arising from market inefficiency. As a result, adjusted returns in the neglected sector of the market will not exceed the market barrier for any length of time. One should remember, however, that some of the constraints- "prudence," for example-that create the market barrier are not monetary. Thus the barrier might in fact be much higher than relative earning potential alone.

Finally, one should also remember that in the competitive environment of many financial institutions, managers' investment decisions are highly restricted by considerations of self-preservation. Investment managers might avoid opportunities in the neglected segment of the market and "play it safe" even when the possible gains are high enough to warrant taking the risk from the standpoint of the financial institution itself. This simply implies that managers 
of some financial institutions may have other goals in addition to maximizing the market value of their institution.

All these factors create some interesting opportunities for noninstitutional investors and for financial institutions able and willing to explore neglected ground. The magnitude of these opportunities is closely related to the size of the institutional market barrier. Unfortunately, the size is hard to gauge because we have no way of (a) separating the superior returns on neglected securities into information deficiency and market barrier components or (b) measuring, in monetary terms, all the factors responsible for the barrier's existence. We can, however, suggest some principles for exploiting the neglected firm effect.

\section{Investment Implications}

With the prospect of higher returns on neglected securities, financial institutions might consider investing part of the predesignated less liquid portion of their portfolios in neglected companies; this may be the best way for large institutions, in particular, to participate in the neglected segment of the market. Institutions might also consider creating funds of neglected securities. It would then be easier to employ screening procedures to overcome some of the information deficiencies associated with neglected companies.

The investment opportunities for small institutions are particularly promising. The neglected firm effect exists not only for small, but also for medium-size, firms (see, for example, the risk adjusted returns in the second column of Table III); although large institutions are likely to consider these firms inappropriate investments, their size may be no barrier to smaller institutions. Furthermore, many small financial institutions will have a comparative advantage over individual investors in researching and screening securities, hence will be less affected by the information deficiency.

\section{Caveats}

In considering the implementation of policies based on the neglected firm effect, investors should keep in mind some important points.

First, systematic pricing inefficiency is unlikely to persist over time for any individual security. The dynamic process of the popularity flow is definitely at work; after an investor discovers a promising neglected stock and pays the price to collect the necessary information to identify the inefficiency, the stock's price will gradually go up. Simultaneously, as the security's popularity increases and better information is produced, the pricing inefficiency will disappear.

To ameliorate this self-destruction problem, the investor should continually update the neglected portfolio to reflect changes in the focus of institutional investors' attention and the resulting information consequences. This can be done by an investment policy that closely follows the popularity flow-i.e.; selling the securities that cease to be neglected (taking the profit) and buying new neglected companies. ${ }^{8}$ It is not very likely that all securities will be followed with the same intensity all the time. 
Second, the pricing inefficiency, if it exists, cannot be exploited without additional information and analysis. The inefficient pricing process is a two-sided coin: Some securities might be overpriced, others underpriced. There is no way of knowing a priori which is the case for a particular security.

Finally, if pricing inefficiency does not exist - i.e., if the higher returns on neglected securities are exactly offset by the information deficiency (or the cost of eliminating same)-then investors face a tradeoff between higher return and certainty of information. Investors should realize that such tradeoffs exist, try to quantify them and make their choice based on their own personal (institutional) preferences. Although, under this scenario, the lunch is not free, it might be well worth the price for some investors.

In greatly oversimplified terms, our results and their practical implications can be summarized by the Giraffe Principle:

If, by reason of structure, giraffes are doomed to forage among the high trees, smaller animals (not excluding short giraffes that are willing to bend their necks) should contemplate the exciting opportunities existing in the neglected, somewhat gray area down below.

As long as it is not overdone, such a policy could indeed be rewarding.

\section{Footnotes}

1. See Avner Arbel and Paul Strebel, "The Neglected and Small Firm Effects," The Financial Review, November 1982, pp. 201-218 and Arbel and Strebel, "Pay Attention to Neglected Firms," The Journal of Portfolio Management, Winter 1983, pp. 37-42.

2. The study presented here differs from the previous ones also in expanding the investigation beyond the Standard \& Poor's 500 to include companies from the American Stock Exchange and over-the-counter markets that are even more neglected.

3. Standard \& Poor's Corporation, Stock Guide, monthly publications, 1971-1980. The average number of financial institutions holding a security for January and July was taken as a proxy for the typical yearly institutional holding. (Calculations were repeated also for January and July holdings separately. The results were not significantly different and are consistent with the conclusions presented in this article.) The classification was done by splitting the sample into approximately three equal groups. Companies held by more than 12 financial institutions were classified as ICR 1 , two to 12 as ICR 2 and those held by just a single institution, or not even by one, were classified as ICR 3.

4. For a good summary of the small firm effect, see Solveig Jansson, "The Big Debate Over Little Stocks," Institutional Investor, June 1982, pp. 141-148.

5. In addition to the traditional ordinary least squares method of computing beta, we employed the aggregated coefficients method proposed by Elroy Dimson (in "Risk Measurement When 
Shares are Subject to Infrequent Trading," Journal of Financial Economics, 1979, pp. 197-226). The latter is designed to overcome the beta measurement problems caused by infrequent trading. In this study, however, infrequent trading was less of a problem, owing to the use of monthly, rather than daily, return data. Since the Dimson beta results were similar in relative magnitude to the ordinary least squares results, only the latter are reported here.

6. Combining the risk measures with the returns and accounting for the risk-free rate, one obtains the Treynor and Sharpe indexes of portfolio performance. The Sharpe index is defined as

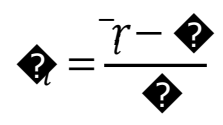

and the Treynor index is:

where

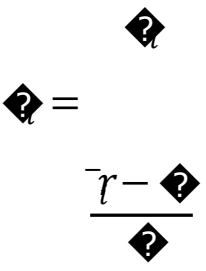

$$
\begin{aligned}
& -r=\text { average return on portfolio i, } \\
& R \text { = standard deviation of returns for portfolio i, } \\
& R=\text { risk-free rate. }
\end{aligned}
$$

A good discussion of the two indexes is contained in Jack Francis, Investment Analysis and Management, Third Edition (New York: McGraw-Hill, 1980), pp. 600-605.

7. The beta coefficients and the unsystematic risk measures are based on the equally weighted Wilshire 5000 index. Similar results were generated by the value-weighted Wilshire index. Owing to the difference in the index weighting schemes, the size effect turns out to be stronger when measured with the use of the value-weighted index. Most importantly, however, the neglected firm effect remains equally significant regardless of which index is used.

8. The portfolios in our study were turned over once a year to adjust to changes in the degree of institutional holding. It seems that better results can be obtained by more frequent turnover. We are now checking this question in a study of the dynamics of the popularity flow and the neglected firm effect. 